\begin{abstract}
HHS Public Access
Author manuscript

Psychiatry Res. Author manuscript; available in PMC 2018 July 30.

Published in final edited form as:

Psychiatry Res. 2017 July 30; 265: 26-34. doi:10.1016/j.pscychresns.2017.05.003.

\section{Resting State Functional Connectivity in Primary Insomnia, Generalized Anxiety Disorder and Controls}

\author{
Edward F. Pace-Schott ${ }^{a, b}$, Jared P. Zimmerman ${ }^{a, b}$, Ryan M. Bottary ${ }^{a, b}$, Erik G. Lee ${ }^{a, b}$, \\ Mohammed R. Milad ${ }^{a, b}$, and Joan A. Camprodon ${ }^{a, b}$ \\ aDepartment of Psychiatry, Massachusetts General Hospital, Harvard Medical School, \\ Charlestown MA, USA \\ ${ }^{\mathrm{b}} \mathrm{MGH} / \mathrm{HST}$ Martinos Center for Biomedical Imaging, Charlestown, MA, USA
}

\section{Abstract}

Sleep abnormalities are extremely common in anxiety disorders and may contribute to their development and persistence. Their shared pathophysiological mechanisms could thus serve as biomarkers or targets for novel therapeutics. Individuals with Primary Insomnia were age- and sex-matched to controls and to persons with Generalized Anxiety Disorder. All underwent fMRI resting-state scans at 3-T. In Primary Insomnia and controls, sleep was recorded for 2 weeks using diaries and actigraphy. All participants completed state-anxiety and neuroticism inventories. Whole-brain connectivity of 6 fear- and extinction-related seeds were compared between the 3 groups using ANOVA. The only significant between-group main effect was seen for connectivity between the left amygdala seed and a bilateral cluster in the rostral anterior cingulate cortex. The latter is believed to exert top-down control over amygdala activity and their interaction may thus constitute an emotion regulatory circuit. This connectivity was significantly greatest in controls while Primary Insomnia was intermediate between that of controls and Generalized Anxiety Disorder. Across Primary Insomnia and control subjects, mean connectivity decreased with poorer sleep. Across all 3 groups, connectivity decreased with greater neuroticism and pre-scan anxiety. Decreased top-down control of the amygdala may increase risk of developing an anxiety disorder with preexisting Primary Insomnia.
\end{abstract}

\footnotetext{
* Corresponding author. Edward F. Pace-Schott, Ph.D. Harvard Medical School, Massachusetts General Hospital - East, CNY 149 13th Street, Room 2605, Charlestown, MA 02129, USA, Tel.: 508-523-4288; fax: 617-726-4078. epace-schott@ mgh.harvard.edu.

Publisher's Disclaimer: This is a PDF file of an unedited manuscript that has been accepted for publication. As a service to our customers we are providing this early version of the manuscript. The manuscript will undergo copyediting, typesetting, and review of the resulting proof before it is published in its final citable form. Please note that during the production process errors may be discovered which could affect the content, and all legal disclaimers that apply to the journal pertain.

Financial disclosures

None of the authors report potential conflicts of interest.

Contributions

Edward F. Pace-Schott designed experiment, collected data, analyzed data, interpreted findings, wrote manuscript Jared P. Zimmerman analyzed data, interpreted findings, wrote manuscript

Ryan M. Bottary collected data, analyzed data

Erik G. Lee analyzed data, interpreted findings, wrote manuscript

Mohammed R. Milad designed experiment, interpreted findings

Joan A. Camprodon interpreted findings, wrote manuscript
} 


\section{Keywords}

sleep disorders; primary insomnia; resting state functional connectivity; generalized anxiety disorder; anxiety disorders; biological markers

\section{Introduction}

Insomnia can be formulated as an anxiety-related disorder in which the anxious thoughts and feelings pertain to sleep itself (Baglioni et al., 2010a; Baglioni et al., 2014). However, more general emotional dysregulation is also common in insomnia as reflected in personality variables (van de Laar et al., 2010) such as a tendency to internalize conflict (Kales et al., 1983) as well as the high comorbidity with mood and anxiety disorders (Alvaro et al., 2013; Baglioni et al., 2011; Riemann, 2007; Stepanski and Rybarczyk, 2006). Such findings have led to the suggestion that emotional reactivity is both a risk and a perpetuating factor for the development of chronic insomnia (Baglioni et al., 2010b; Espie, 2002).

Contributing to this emotional dysregulation is now well-replicated evidence for chronic hyperarousal in insomnia (Riemann et al., 2010) manifested in peripheral (Bonnet and Arand, 2010) and central (Kay et al., 2016; Nofzinger et al., 2004) physiology (albeit to a lesser extent) as well as in cognitive style (e.g., rumination, neuroticism, anxious attentiveness) (Fernandez-Mendoza et al., 2010; Harvey, 2002) and sensitivity of sleep quality to acute stress (Drake et al., 2011). Primary Insomnia (PI) can therefore be considered as a neuropsychiatric syndrome with affective, behavioral and cognitive maladaptive dimensions, in addition to autonomic changes. In the current study, we show that, in Primary Insomnia (PI), resting state functional connectivity (rsFC) between the left amygdala and a key emotion regulatory area in the rostral anterior cingulated cortex (rACC) is intermediate between what is seen in healthy good-sleepers (GS) and individuals with Generalized Anxiety Disorder (GAD)..

Disrupted sleep is increasingly viewed as a causative contributing factor in the development of psychiatric conditions, and not just a symptom common to mood and anxiety disorders (Harvey, 2011; Pace-Schott et al., 2015b). Although a number of studies suggest that anxiety disorders most often precede or emerge simultaneously with insomnia (Johnson et al., 2006; Ohayon and Roth, 2003), for a significant number of individuals, preexisting insomnia also increases the odds of incident anxiety disorders (Breslau et al., 1996; Ford and Kamerow, 1989). For example, in a large European sample, insomnia was present before the onset of anxiety disorders in $18 \%$ of those with first-episode anxiety disorders and $23.2 \%$ of those with recurrent anxiety. Additionally, elevated odds ratios for incident anxiety disorders have been reported among those with pre-existing insomnia with magnitudes of 1.97 (Breslau et al., 1996), 2.3 (Jansson-Frojmark and Lindblom, 2008), 2.6 (Ford and Kamerow, 1989), and 3.4 (Neckelmann et al., 2007). Importantly, the diagnosis of PI (APA, 2000) rules out sleep difficulties secondary to another Axis 1 disorder, hence, those with PI may represent the subset of individuals for whom preexisting insomnia could predispose them to an incident anxiety disorder. GAD is the anxiety disorder most commonly diagnosed comorbidly with insomnia disorder (Ohayon et al., 1998), and more than half of patients with GAD report 
insomnia as a core symptom of the syndrome (Belanger et al., 2004). Given these multiple clinical associations, and the formulation of PI as a neuropsychiatric syndrome, we hypothesize that abnormalities in connectivity seen in GAD relative to healthy controls may also be present in those with PI, for whom these abnormalities may constitute a risk for later development of comorbid GAD.

By examining low frequency oscillations $(0.008-0.1 \mathrm{~Hz})$ of the blood oxygen dependent (BOLD) fMRI signal during resting wakefulness, investigators have described at least seven widely distributed and highly stable brain networks (Fox and Raichle, 2007; Fox et al., 2005; Fox et al., 2009; Raichle, 2011). These include the default mode network (DMN: anterior and posterior midline and inferior parietal cortices, hippocampal formation), the salience network (SN: amygdala, dorsal anterior cingulate and insular cortices), a central executive network (CEN: dorsolateral prefrontal and parietal cortices), a dorsal attention network (frontal and parietal networks) and, three networks corresponding to processing in the major sensory modalities (Peterson et al., 2014; Raichle, 2011; Seeley et al., 2007; Yeo et al., 2011).

Resting state functional connectivity (rsFC) has increasingly been used to characterize and compare brain networks in psychiatric disorders including anxiety disorders [for a recent review see (Peterson et al., 2014)]. In GAD, rsFC studies suggest abnormal amygdala engagement with brain networks that normally regulate anxiety (Etkin et al., 2009; Oathes et al., 2015). For example, in healthy controls, clearly differentiated resting-state connectivity was seen between an amygdala input structure, the basolateral nucleus (BLA) that is connected with widespread areas of the cortex, and an amygdala output structure, the centromedial nucleus (CMA) that is connected with subcortical regions including thalamus, brainstem, and cerebellum (Etkin et al., 2009). In individuals with GAD, however, this functional segregation of connectivity between BLA and CMA was reduced and less well organized (Etkin et al., 2009). In particular, amygdala connectivity was reduced within areas of the SN. In contrast, amygdala connectivity was increased within areas of the CEN, the latter being interpreted as compensatory, top-down efforts to self-regulate anxiety (Etkin et al., 2009). In contrast, other rsFC studies linked GAD with reduced connectivity between the amygdala and regulatory frontal regions such as the dorsolateral prefrontal cortex and suggest reduced top-down control of negative emotion (Liu et al., 2015).

Although Insomnia Disorder has been, to date, understudied using rsFC, a number of recent reports show both hypo and hyper-connectivity in PI compared to controls. In one such study, a seed region in the left amygdala showed reduced functional connectivity with areas in the left insula, bilateral striatum and thalamus in PI compared with healthy controls (Huang et al., 2012). Although these investigators interpreted such decreased connectivity of the amygdala as evidence for impaired emotional processing in PI, their use of a clusterbased analyses with high rates of false positive results (Eklund et al., 2016) calls into question these findings. A more recent study that - that followed the more stringent recommendations for controlling false positives suggested by Eklund et al. (including a cluster-defining threshold of $\mathrm{p}<0.001$ ) showed hyper-connectivity in PI between the insula and rACC suggesting increased connectivity within the SN (Wang et al., 2017), a finding consonant with hypothesized hyperarousal underlying PI (Bonnet and Arand, 2010; 
Riemann et al., 2010). A number of recent studies have used also novel rsFC measures to compare PI to controls.

For example, Zhou et al. (2016) used brain entropy (a measure of temporal randomness) to identify regions differing between individuals with PI and healthy controls followed by rsFC to test connectivity among these regions. Findings primarily showed greater brain entropy and reduced rsFC in PI within important brain structures (e.g., hippocampus) and networks (e.g., DMN), and these rsFC differences correlated with scores on the Pittsburgh Sleep Quality Index (PSQI, Buysse et al., 1989b). Other such rsFC measures used to compare PI and controls include amplitude of low frequency fluctuations (ALFF) and regional homogeneity (ReHo), and investigators using these approaches have suggested that differences may reflect hyperarousal in PI (Dai et al., 2016; Dai et al., 2014; Li et al., 2016a). Importantly, these measures have also been shown to correlate with PSQI scores. For example, PSQI global scores positively correlated with temporal regions where, in males, ALFF in PI exceeded that of good-sleepers (Dai et al. 2016). These investigators suggest that greater activation in these temporal areas is associated with hyperarousal. In another study, ALFF in an inferior parietal area negatively correlated with PSQI global scores (Li et al. 2016a). These investigators suggest lowered ALFF in these regions may reflect lowered restorative activity in the DMN resulting from poor sleep. In another study, among PI, ReHo showed a negative relationship with PSQI in frontal areas, a finding investigators associated with deficits in emotion regulation (Dai et al. 2014). In investigations of DMN connectivity in PI, one study reported reduced rsFC between key components of the DMN compared with controls (Nie et al., 2015). Another group found no differences in DMN rsFC between PI and good sleepers but found that greater DMN rsFC during wakefulness predicted poorer sleep quality, a finding they suggested may reflect the association of ruminative mentation with both DMN activity and with insomnia (Regen et al., 2016). An additional seed-based rsFC study reported altered functional connectivity between the superior parietal lobe and frontal areas in PI compared to controls (Li et al., 2014).

In the current study, we test the hypothesis that rsFC of fear circuitry will reveal shared pathophysiological mechanisms between PI and GAD, with potential value as a biomarker or therapeutic target. Functioning of fear circuitry, and related fear-extinction networks are important determinants of individual differences in emotion regulation and risk for anxiety disorders (Milad and Quirk, 2012; Shin and Liberzon, 2010). Hence rsFC of these regions might be expected to differ between groups with differing degrees of persistent anxiety (Etkin et al., 2009; Oathes et al., 2015). If PI is indeed a risk factor for anxiety disorders and GAD in particular, we should expect a progression of abnormality with PI occupying an intermediate position between GS and GAD. Deficient extinction, in particular, has been widely linked to behavioral and physiological features of anxiety disorders (Graham and Milad, 2011), and effects of sleep quality on extinction have also been reported (Pace-Schott et al., 2015a). Therefore, in the following report, regions of interest (ROI) that have known fMRI task-based associations with fear conditioning and extinction (Milad and Quirk, 2012) (bilateral amygdala, ventromedial prefrontal cortex and dorsal anterior cingulate cortex) were selected to be compared for whole-brain rsFC patterns between GS, PI and GAD. 


\section{Methods}

\subsection{Participants}

Resting state fMRI data were obtained from 13 individuals with DSM-IV-R (APA, 2000)

Primary Insomnia. Comorbid Axis 1 psychiatric disorders were ruled out using the Structured Clinical Interview for DSM-IV-TR Axis I Disorders-Non-Patient Edition (SCID 1/NP) (First et al., 2007). PI and GS participants were screened for other sleep disorders using the Pittsburgh Structured Clinical Interview for Sleep Disorders (unpublished investigator-administered instrument).

All PI participants scored > 15 on the Insomnia Severity Index (ISI) (Bastien et al., 2001) (except one scoring 13) and exceeded the threshold for clinical sleep disturbance (global score > 5) on the PSQI. All PI met criteria for DSM-5 Insomnia Disorder (Persistent, no comorbidities) (APA, 2013, see Supplementary Methods). For brevity, the diagnosis "Primary Insomnia" (PI) is used here, however it is recognized that this is an outdated term equivalent to the above DSM-5 specification. Thirteen GS control subjects were age- and sex-matched to each PI, showed no Axis 1 psychiatric or sleep disorders, and had ISI $\leq 3$ and PSQI < 4. GS and PI subjects were screened using ambulatory polysomnography (PSG) to exclude any clinically significant obstructive sleep apnea (OSA) or periodic limb movement disorder (PLMD). Using archival data drawn from a comprehensive study on extinction memory across the anxiety disorders, 12 of a total 25 individuals who met SCID $1 / \mathrm{NP}$ criteria for GAD as a primary diagnosis were selected. This selected GAD subset were those who: 1) could be age- and sex-matched to a specific PI subject, and 2) were free of psychiatric medication (except 1 on a steady dose of fluoxetine for 2 years).

Although GAD subjects had not been specifically screened for sleep complaints, 11 of the 12 endorsed difficulty initiating or maintaining sleep on the SCID 1/NP. Current and lifetime comorbidities existed among GAD subjects. For current comorbidity, 3 met criteria for obsessive compulsive disorder (OCD), 2 for specific phobia, 2 for SAD and 1 for dysthymia. For lifetime occurrence, 7 met criteria for major depressive disorder, 2 for OCD, 3 for substance abuse, 1 for eating disorder and 1 for panic disorder. Therefore, unlike GS and PI in whom diagnoses other than insomnia in PI were ruled out, those with GAD displayed significant psychopathology. Subjects in all 3 groups were right handed, free of any neurological or major medical illness and were not taking psychiatric or sleep medication (excepting the $1 \mathrm{GAD}$ above). Sex ratio (identical between groups), and mean, median and range of ages are given in the first 4 rows of Table 1 .

\subsection{Protocol}

After clinical and sleep interviews, GS and PI (but not GAD) participants completed 14 days of wrist actigraphy and sleep diaries using the Evening-Morning Sleep Questionnaire (EMSQ) (Pace-Schott et al., 1994; Pace-Schott et al., 2005). Alcohol and recreational drugs were proscribed during these 14 days.

All participants (GS, PI and GAD) were given a urine toxicology screen for illegal substances and, if positive, were discontinued in the study. In addition to the above proscriptions, caffeine and daytime napping were additionally proscribed on the 2 
experimental days. Each PI and GS subject underwent a total of 3 nights of ambulatory PSG using the Somte-PSG monitor (Compumedics USA, Inc., Charlotte, NC). (See Supplementary Methods for montage.) GAD subjects underwent identical scanning procedures but no sleep measures were made and no pre-MRI prescriptions or proscriptions were requested. All PI and GS participants' scans all took place between 16:00 and 22:00.

GAD participants' scanning sessions took place at variable times of day between 09:00 and 20:00. It is recognized that sleep may occur during resting-state scans (Tagliazucchi and Laufs, 2014) thus all participants were instructed to remain awake with eyes open and fixated throughout the resting-state scan. All responded promptly to questions asked immediately following this scan indicating wakefulness at this time.

\subsection{Resting state functional connectivity (rsFC)}

Functional connectivity analysis employed a regional approach based on Biswal et al. (Biswal et al., 1995) and extended in Fox et al. (Fox et al., 2005) and Vincent et al. (Vincent et al., 2006). Scans took place in a 3-Tesla Siemens Magnetom TrioTim Syngo scanner magnet. After an automated scout image was acquired and shimming procedures were performed to optimize field homogeneity, high-resolution 3D MEMPRAGE sequences (TR/ TE1,2,3,4/flip angle $=2530 \mathrm{~ms} / 1.64,3.5,5,36,7.22 \mathrm{~ms} / 7^{\circ}$ ) with an in-plane resolution of 1.0 $\mathrm{mm}$, and $1 \mathrm{~mm}$ slice thickness, were collected. Following T1 MEMPRAGE anatomical scans, 10-minute resting state scans were performed with subjects' eyes open and fixated. Forty-eight slices per TR were obtained with $2.5 \mathrm{~mm}$ slice thickness, $3 \times 3 \mathrm{~mm}$ in-plane resolution, $\mathrm{TR}=2560 \mathrm{~ms}, \mathrm{TE}=30 \mathrm{~ms}$ and flip angle $=90^{\circ}$.

Pre-processing was done with in-house scripts and SPM8 using standard procedures in accordance with Van Dijk et al. (2010). The first 4 volumes were dropped and data then underwent slice-time correction, realignment, spatial normalization and registration to a 3 $\mathrm{mm}$ isotropic MNI template, $6 \mathrm{~mm}$ isotropic FWHM Gaussian smoothing and band-pass filtering between 0.01 and $0.08 \mathrm{~Hz}$. The following sources of spurious variance were then removed from the data through linear regression: (i) six parameters obtained by rigid body correction of head motion plus their first temporal derivative, (ii) the whole-brain signal averaged over a fixed region in atlas space, and (iii) the signal from a ventricular region of interest and a region centered in the white matter. In this manner, variance unlikely to be involved in spatially specific regional correlations was removed from the data.

Global signal regression (GSR) is a controversial data processing step (Anderson et al., 2011; Fox et al., 2009; Murphy et al., 2009) that warrants careful consideration by investigators. Primary criticisms of GSR are that it: 1 ) negatively biases correlations by mandating an approximately zero-meaned distribution of correlation constants, and 2) can alter the interregional correlations within groups and thereby complicate group comparisons (Saad et al., 2012).

Recent studies have largely addressed these issues empirically by demonstrating that GSR: 1) helps improve the correspondence in anti-correlated networks between rs-fMRI and intracranial electrocorticographic recordings in the same subjects (Keller et al., 2013), and 2) is a powerful tool for removing motion artifact which accounts for a significant portion of the globally shared variance (Power et al., 2014). Additionally, Power et al. (2014)

Psychiatry Res. Author manuscript; available in PMC 2018 July 30. 
demonstrated that, in contrast to criticism (Saad et al., 2012), application of GSR actually decreases observed group differences. More recently, GSR has been shown to be especially effective at removing correlations of connectivity with subject motion (Ciric et al., 2017). Given these considerations, we feel GSR is an appropriate processing technique in this study.

Following pre-processing, maps of functional connectivity were obtained by plotting the correlation strength between the mean time course of a seed region to that of each voxel. Key nodes in fear and extinction networks were selected as seed regions and included left and right amygdala, ventromedial prefrontal cortex (vmPFC) and dorsal anterior cingulate cortex (dACC) (Graham and Milad, 2011; Milad and Quirk, 2012). Amygdala seeds were defined for the left $(-24,-4,-18)$ and right $(26,0,-22)$ amygdala as $6 \mathrm{~mm}$ spheres centered on the peak voxels in the Harvard-Oxford subcortical atlas (Jenkinson et al., 2012). Cortical seed regions were defined from a meta-analysis of 298 fear-related studies included in the NeuroSynth database (www.neurosynth.org) (Yarkoni et al., 2011) by creating $6 \mathrm{~mm}$ spheres around identified peak voxels in 2 vmPFC ROIs at 6, 40,-20 and 0, 16, -18 (the latter corresponding to the subgenual ACC). Seed regions were similarly created for 2 ROIs identified in the dACC at 0,24, 22 and 0, 14, 28. Whole-brain seed-based functional connectivity analyses were performed at the individual subject level. Group level wholebrain analyses were conducted with a $3 \times 1$ between-subjects ANOVA model investigating the differences in fear network functional connectivity between GS, PI and GAD subjects.

Corrections for multiple comparisons were conducted using the cluster-extent based thresholding approach in AFNI's 3dClustSim. It has been recently demonstrated (Eklund et al., 2016) that some cluster-extent based thresholding approaches, including 3dClustSim, can lead to inflated false positive rates. In response to this finding, an updated version of $3 \mathrm{dClustSim}$ (from AFNI Version 16.2.09, August $6^{\text {th }}, 2016$ ), incorporating a new mixed autocorrelation function model proposed in Cox et al. (Cox et al., 2016), was used for calculating family wise error (FWE) rates. Further, as cluster defining thresholds (CDTs) of $p=.01$ were also shown to produce inflated rates of false positives (Eklund et al., 2016), the CDT for these analyses was set to $p=.005$. Anatomical localization of peak voxels was estimated using the Yale BioImage Suite (http://bioimagesuite.yale.edu) MNI to Talairach Coordinate Converter with Brodmann Areas (http://sprout022.sprout.yale.edu/mni2tal/ mni2tal.html).

To examine the clinical and behavioral relevance of group differences in connectivity, zscores were extracted from each voxel in significant clusters and averaged to get a mean cluster connectivity score for each subject. The relationship of mean cluster z-scores with the measures of sleep, anxiety and neuroticism described below were then examined using simple regression.

\subsection{Sleep questionnaires (GS and PI only)}

The Insomnia Severity Index (ISI) (Bastien et al., 2001) and PSQI are the standard instruments used to quantify insomnia and retrospective assessment of sleep quality respectively. The Evening-Morning Sleep Questionnaire (EMSQ) provides measures of 
subjective total sleep time (TST), sleep onset latency (SOL) and sleep efficiency (SE). See

Supplementary Methods for details on ISI, PSQI and EMSQ.

\subsection{Measures of state anxiety and trait neuroticism}

All participants completed the Spielberger State-Trait Anxiety Inventory (STAI) State version (Spielberger et al., 1990)--a validated measure of state anxiety--30-60 min before beginning their resting-state scan. GS and PI participants completed the Revised NEO Personality Inventory (NEO-PI-R) (Costa and McCrae, 1992) while GAD participants completed the NEO Five-Factor Inventory (NEO-FFI) (Costa and McCrae, 1992). Scores for the Neuroticism domain of both the NEO-PI-R and the NEO-FFI were converted to $z$-scores using population means (combined men and women) for the respective tests (Costa and McCrae, 1992) and were then converted to $T$-scores based on population norms to equate NEO-PI-R and NEO-FFI scores.

\subsection{Actigraphy}

GS and PI participants wore the Actiwatch-2 (Philips Respironics, Bend, OR) continuously for at least 14 days (mean 15.4, range 9-21) and 4 participants (3 GS, 1 PI) were not analyzed due to device malfunction (Supplementary Methods). Participants pressed an event-marker button when beginning to attempt sleep and when waking for the day and time stamps defined time-in-bed. Movement data was collected in 1-min epochs and analyzed using the default algorithm of Actiware 5.61 software. Within time-in-bed, the default algorithm scored sleep onset at the beginning of the first continuous 10 immobile minutes and thereafter via algorithm (Supplementary Methods). Sleep Efficiency was computed as total sleep epochs in minutes divided by total time between event marks $\times 100$.

\section{Results}

\subsection{Group differences in whole-brain functional connectivity with ROI seeds}

Among the 6 seeds, only the left amygdala showed a significant group (GS vs. PI vs. GAD) main effect for connectivity in 1-way ANOVA. Using a CDT of $p=0.005$, only a single above-threshold cluster of 76 voxels appeared for connectivity between the left amygdala and a bilateral rACC region (peak voxel 9, 44, 14; $F=14.52, z=4.05$, FWE=0.02; Figure 1). The Yale BioImage Suite locates coordinates of this peak voxel in Brodmann Area (BA) 32 in the left hemisphere and at the boundary of areas 32 and 10 in the right hemisphere, though the cluster extended into BA 32.

This finding was also significant in the GS > GAD contrast and consisted of a 143-voxel cluster with the same peak voxel $(9,44,14)$ that was significant at a CDT of $\mathrm{p}=0.005$ $(T=5.39, z=4.57)$ at a FWE of $p=0.01$ (Figure $2 \mathrm{~A}$ ). The GS $>$ GAD comparison remained significant even at a CDT of $p=0.001$ and a FWE of $p=0.03$, appearing as bilateral clusters with left and right peak voxels of $-9,44,14$ (28 voxels) and 9, 44, 14 (36 voxels) respectively. According to our stringent CDT, the GS > PI contrast was trending toward significance with a CDT slightly above 0.005 ( 74 voxels; CDT p=0.007; $T=4.00, z=3.61$; FWE $p=0.05$; Figure $2 \mathrm{~B}$ ), a finding significant by traditional standards. 


\subsection{Correlations of extracted connectivity with measures of sleep quality in GS and PI}

GS participants showed significantly better retrospective and diary-based sleep quality than PI (Table 1). Across GS and PI subjects, mean z-values extracted from the cluster corresponding to the above ANOVA group main effect for left amygdala to rACC connectivity correlated significantly with retrospective and longitudinally measured sleep quality. Connectivity varied negatively with ISI $(R=-0.52, p=0.008)$ and global PSQI $(R=$ $-0.50, p=0.011$ ) (i.e., lower connectivity $z$-scores were associated with worse sleep quality measures). Connectivity varied positively with increasing diary-reported mean $\mathrm{SE}(R=0.41$, $p=0.039$, Figure $3 \mathrm{~A}$ ) but not with actiwatch-measured SE. Therefore, lower connectivity zscores were associated with lower subjective, but not objective estimates of sleep time as a percentage of total time in bed. In addition, connectivity varied negatively with both diaryreported $(R=-0.40, p=0.044$, Figure $3 \mathrm{~A})$ and actigraph-measured mean SOL $(R=-0.35$, $p=0.079$, Figure $3 \mathrm{C}$ ). Therefore, lower connectivity $\mathrm{z}$-scores were associated with subjectively and objectively delayed sleep initiation. These correlations were driven by group differences and, within groups, z-scores did not significantly correlate with diary- or actigraph-reported measures (see Supplementary Results). However, correlation coefficients of diary sleep parameters with z-scores in GS were in the expected direction with a trend for PSQI $(R=-0.50, p=0.08)$.

\subsection{Correlations of extracted connectivity with neuroticism and state anxiety in all 3 groups}

Absolute mean T-values of neuroticism were least in GS, intermediate in PI and maximal in GAD (Table 1). Bonferroni-corrected post-hoc comparisons showed significantly higher neuroticism in GAD compared to both GS and PI $(p \leq 0.0001)$ but a trend between GS and PI ( $p=0.073$ ). For individual subjects across all 3 groups, mean $\mathrm{z}$-values in the cluster corresponding to the above ANOVA group main effect decreased with increasing neuroticism $(R=-0.44, p=0.005$, Figure $4 \mathrm{~A})$.

State anxiety prior to the resting state scan was greatest in GAD but equal in GS and PI (Table 1). Across all 3 groups, mean connectivity between the left amygdala and rACC was lower with increasing state anxiety $(R=-0.35, p=0.038)$.

\section{Discussion}

In good sleepers compared to both persons with PI and those with GAD, greater rsFC was seen between the left amygdala and a bilateral region of the rACC that extended anteriorly beyond the cingulate sulcus into caudal medial prefrontal areas. Among an additional 5 seed regions comprising other known portions of fear and extinction circuitry, the main effect of group (i.e., GS vs. PI vs. GAD) did not reach significance.

The current finding suggests one potential mechanism by which pre-existing insomnia may increase vulnerability to an incident anxiety disorder. The rACC is part of a prefrontal network responsible for top-down control of amygdala activity (Dodhia et al., 2014; Pizzagalli, 2011). Thus, both PI and GAD share diminished connectivity in this emotional regulatory circuit relative to GS and, in those individuals for whom development of PI 
precedes development of GAD, this deficit could increase their tendency to generalize anxiety beyond concerns specifically dealing with sleep (Pace-Schott et al., 2015b). Indeed, persons with insomnia show greater levels of neuroticism by a variety of measures (van de Laar et al., 2010) and, in the current study, post-hoc comparisons showed elevated neuroticism in PI compared to GS.

It is noteworthy that a number of rsFC studies utilizing indices such as brain entropy, ALFF and ReHo have suggested reduced organization of interregional connectivity in PI compared to controls as well as further evidence of hyperarousal in PI (Dai et al., 2016; Dai et al., 2014; Li et al., 2016a; Zhou et al., 2016). Thus, in insomnia, top-down emotion-regulatory structures such as the rACC may have reduced influence on subcortical emotion-generative structures, such as the amygdala, due to abnormalities in intrinsic properties of neuronal activity. Abnormality may also extend to the brain's structural connectivity. Notably, in GAD, a diffusion-tensor imaging (DTI) study suggested reduced white matter integrity (fractional anisotropy; FA) in the uncinate fasciculus, a major fronto-limbic tract connecting the prefrontal cortex with the amygdala (Tromp et al., 2012). These investigators suggest that such reduced structural connectivity may represent a basis for reduced top-down control of negative emotions in GAD. Similarly, in PI, reduced FA has been reported in multiple white matter tracts, and reduced FA correlated with both PSQI and duration of PI (Li et al., 2016b). Hence GAD and PI may share disruption of axonal connectivity resulting in diminished top-down emotional regulation.

A yet more specific, albeit highly speculative, pathophysiological mechanism is suggested by two additional studies. First, a recent rsFC study showed hyper-connectivity, in PI, between the left insula and a region of the right $\operatorname{rACC}(9,45,21)$ (Wang et al., 2017) that is in close proximity to the region identified as hypo-connected to the left amygdala in the current study $(9,44,14)$. Second, a structural MRI study revealed hypertrophy of the rACC in PI compared to controls, which correlated with the extent of sleep disturbance and which these investigators interpreted as a compensatory response to prolonged sleep disturbance (Winkelman et al., 2013). Thus excessive self monitoring in PI, associated with attempts to initiate sleep in a hyperaroused state, may lead to excessive interoceptive information impinging on the rACC from the insula leading to dysfunction of the rACC, with impaired rACC ability to regulate amygdala activity and increased vulnerability to anxious symptoms.

Left amygdala to rACC mean $z$-scores, across subjects, diminished with poorer sleep, greater neuroticism and greater pre-scanning state anxiety. Such correlation of connectivity scores with multiple domains of functioning suggests a dimensional clinical significance to these resting state findings, beyond syndromal classifications. Although the sleep quality of GAD subjects was not assessed, its reduction relative to GS can be assumed from their statements on the SCID as well as from the well-replicated relationship between measures of anxiety and neuroticism (on which GAD scored maximally) and those of subjective sleep quality (e.g., Pace-Schott et al., 2015c).

The finding of group differences in connectivity to the left but not right amygdala is of interest. There is some evidence of greater discrimination of fear stimuli in the left versus right amygdala (Hardee et al., 2008). Moreover, left lateralization of amygdala activation 
with emotional memory in females contrasts with right lateralization in men (Cahill et al., 2004 ) and, in this sample, $89 \%$ of subjects were women.

The current study reports preliminary findings that reflect a number of limitations, and subsequent, planned research will address each of the following. First, the small sample size and predominance of female participants limits generalizability of findings. Second, as a cross-sectional study, one can only speculate that PI may precede and promote incident GAD. Third, the lack of sleep data from the GAD sample precludes consideration of sleep impairment (or exclusion of OSA or PLMD) in this group although, as noted, the SCID 1/NP suggested that at least subjective sleep difficulties were indeed present. Fourth, the lack of sleep-hygiene prior to scanning in the GAD sample might have influenced functional connectivity if some GAD were sleep deprived or had recently drunk caffeine (e.g., Khalsa et al., 2016; Rack-Gomer and Liu, 2012). However such behaviors would not necessarily have systematically altered group findings for GAD. (Urine toxicology screens were obtained for all participants.) Fifth, the differing time of day for scanning GAD compared with the other subjects had the potential to introduce circadian effects (e.g., Pace-Schott et al., 2013). Sixth, obtaining cortical ROI coordinates from a Neurosynth meta-analysis is less desirable than deriving such regions from task-based analyses (e.g., of fear conditioning and extinction) within the current sample itself. However, sufficient numbers of subjects within each condition of this counterbalanced protocol (Milad et al., 2007) were not yet available to conduct task-based analyses. Seventh, the recommended stringent CDT of $\mathrm{p}=.001$ (Eklund et al., 2016) was not achieved for all comparisons. Nonetheless, this level was achieved for the GS > GAD post-hoc analysis which represented the major influence on the 3-group ANOVA finding. Eighth, the correlations of sleep and anxiety measures with mean z-values resulted, to a large extent, from these measures' shared relationship with diagnosis (Table 1). Nonetheless, the amygdala-to-rACC connectivity finding reflected the ANOVA main effect of differences among all 3 groups, whereas variation of mean connectivity with sleep quality was seen among the combined GS and PI without GAD, despite the fact that majority of the ANOVA main effect occurred between GS and GAD (Figure 2). In addition, within GS alone, there were indications of relationships between connectivity and subjective sleep quality. Thus differences between diagnostic groups, although driving statistical significance, were unlikely to have been the sole cause of correlation between connectivity and sleep quality.

In conclusion, findings suggest that resting-state connectivity in GS exceeded both PI and GAD within an emotion regulatory circuit and thus supports the concept of insomnia as a neuropsychiatric condition with affective as well as sleep abnormalities (e.g., Baglioni et al., 2010b). As detailed in the Introduction, although sleep disturbances more often follow or cooccur with associated anxiety disorders, when preexisting primary insomnia occurs, it elevates risk of incident anxiety disorders. The current findings provide preliminary support for the hypothesis that, in this latter case, alteration of emotion regulatory pathways associated with poor sleep may contribute to the observed elevated risk. Additionally, findings support the importance of adequately treating primary insomnia for patients' longterm mental health. 


\section{Supplementary Material}

Refer to Web version on PubMed Central for supplementary material.

\section{Acknowledgments}

Research was supported by National Institute of Mental Health Grant R21MH101567 and the 2015-2016 Harvard Mind/Brain/Behavior Interfaculty Initiative.

\section{References}

Alvaro PK, Roberts RM, Harris JK. A Systematic Review Assessing Bidirectionality between Sleep Disturbances, Anxiety, and Depression. Sleep. 2013; 36:1059-1068. [PubMed: 23814343]

American_Psychiatric_Association. Diagnostic and Statistical Manual of Mental Disorders. Fifth. American Psychiatric Publishing; Arlington, VA: 2013.

Anderson JS, Druzgal TJ, Lopez-Larson M, Jeong EK, Desai K, Yurgelun-Todd D. Network anticorrelations, global regression, and phase-shifted soft tissue correction. Hum. Brain Mapp. 2011; 32:919-934. [PubMed: 20533557]

APA. Diagnostic and Statistical Manual of Mental Disorders DSM-IV-TR. Fourth Edition (Text Revision). American Psychiatric Association; Washington, DC: 2000.

Baglioni C, Battagliese G, Feige B, Spiegelhalder K, Nissen C, Voderholzer U, Lombardo C, Riemann D. Insomnia as a predictor of depression: a meta-analytic evaluation of longitudinal epidemiological studies. J. Affect. Disord. 2011; 135:10-19. [PubMed: 21300408]

Baglioni C, Lombardo C, Bux E, Hansen S, Salveta C, Biello S, Violani C, Espie CA. Psychophysiological reactivity to sleep-related emotional stimuli in primary insomnia. Behav. Res. Ther. 2010a; 48:467-475. [PubMed: 20227678]

Baglioni C, Regen W, Teghen A, Spiegelhalder K, Feige B, Nissen C, Riemann D. Sleep changes in the disorder of insomnia: a meta-analysis of polysomnographic studies. Sleep medicine reviews. 2014; 18:195-213. [PubMed: 23809904]

Baglioni C, Spiegelhalder K, Lombardo C, Riemann D. Sleep and emotions: a focus on insomnia. Sleep medicine reviews. 2010b; 14:227-238. [PubMed: 20137989]

Bastien CH, Vallieres A, Morin CM. Validation of the Insomnia Severity Index as an outcome measure for insomnia research. Sleep medicine. 2001; 2:297-307. [PubMed: 11438246]

Belanger L, Morin CM, Langlois F, Ladouceur R. Insomnia and generalized anxiety disorder: effects of cognitive behavior therapy for gad on insomnia symptoms. J. Anxiety Disord. 2004; 18:561571. [PubMed: 15149714]

Biswal B, Yetkin FZ, Haughton VM, Hyde JS. Functional connectivity in the motor cortex of resting human brain using echo-planar MRI. Magn. Reson. Med. 1995; 34:537-541. [PubMed: 8524021]

Bonnet MH, Arand DL. Hyperarousal and insomnia: state of the science. Sleep medicine reviews. 2010; 14:9-15. [PubMed: 19640748]

Breslau N, Roth T, Rosenthal L, Andreski P. Sleep disturbance and psychiatric disorders: a longitudinal epidemiological study of young adults. Biol. Psychiatry. 1996; 39:411-418. [PubMed: 8679786]

Buysse DJ, Reynolds CF 3rd, Monk TH, Berman SR, Kupfer DJ. The Pittsburgh Sleep Quality Index: a new instrument for psychiatric practice and research. Psychiatry Res. 1989a; 28:193-213. [PubMed: 2748771]

Buysse DJ, Reynolds CF 3rd, Monk TH, Berman SR, Kupfer DJ. The Pittsburgh Sleep Quality Index: a new instrument for psychiatric practice and research. Psychiatry Res. 1989b; 28:193-213. [PubMed: 2748771]

Cahill L, Uncapher M, Kilpatrick L, Alkire MT, Turner J. Sex-related hemispheric lateralization of amygdala function in emotionally influenced memory: an FMRI investigation. Learn. Mem. 2004; 11:261-266. [PubMed: 15169855] 
Ciric R, Wolf DH, Power JD, Roalf DR, Baum G, Ruparel K, Shinohara RT, Elliott MA, Eickhoff SB, Davatzikos C, Gur RC, Gur RE, Bassett DS, Satterthwaite TD. Benchmarking of participant-level confound regression strategies for the control of motion artifact in studies of functional connectivity. Neuroimage. 2017

Costa, PT., McCrae, RR. Revised NEO Personality Inventory (NEO-PI-R) and NEO five-factor inventory (NEO-FFI) Professional Manual. Psychological Assessment Resources, Inc; Odessa FL: 1992.

Cox RW, Reynolds RC, Taylor PA. AFNI and Clustering: False Positive Rates Redux. bioRxiv. 2016:065862.

Dai XJ, Nie X, Liu X, Pei L, Jiang J, Peng DC, Gong HH, Zeng XJ, Wang YX, Zhan Y. Gender Differences in Regional Brain Activity in Patients with Chronic Primary Insomnia: Evidence from a Resting-State fMRI Study. J Clin Sleep Med. 2016; 12:363-374. [PubMed: 26715399]

Dai XJ, Peng DC, Gong HH, Wan AL, Nie X, Li HJ, Wang YX. Altered intrinsic regional brain spontaneous activity and subjective sleep quality in patients with chronic primary insomnia: a resting-state fMRI study. Neuropsychiatric disease and treatment. 2014; 10:2163-2175. [PubMed: 25484585]

Dodhia S, Hosanagar A, Fitzgerald DA, Labuschagne I, Wood AG, Nathan PJ, Phan KL. Modulation of resting-state amygdala-frontal functional connectivity by oxytocin in generalized social anxiety disorder. Neuropsychopharmacology. 2014; 39:2061-2069. [PubMed: 24594871]

Drake CL, Friedman NP, Wright KP Jr, Roth T. Sleep reactivity and insomnia: genetic and environmental influences. Sleep. 2011; 34:1179-1188. [PubMed: 21886355]

Eklund A, Nichols TE, Knutsson H. Cluster failure: Why fMRI inferences for spatial extent have inflated false-positive rates. Proc. Natl. Acad. Sci. U. S. A. 2016; 113:7900-7905. [PubMed: 27357684]

Espie CA. Insomnia: conceptual issues in the development, persistence, and treatment of sleep disorder in adults. Annu. Rev. Psychol. 2002; 53:215-243. [PubMed: 11752485]

Etkin A, Prater KE, Schatzberg AF, Menon V, Greicius MD. Disrupted amygdalar subregion functional connectivity and evidence of a compensatory network in generalized anxiety disorder. Arch. Gen. Psychiatry. 2009; 66:1361-1372. [PubMed: 19996041]

Feige B, Spiegelhalder K, Kiemen A, Bosch OG, Tebartz van Elst L, Hennig J, Seifritz E, Riemann D. Distinctive time-lagged resting-state networks revealed by simultaneous EEG-fMRI. Neuroimage. 2017; 145:1-10. [PubMed: 27637863]

Fernandez-Mendoza J, Vela-Bueno A, Vgontzas AN, Ramos-Platon MJ, Olavarrieta-Bernardino S, Bixler EO, De la Cruz-Troca JJ. Cognitive-emotional hyperarousal as a premorbid characteristic of individuals vulnerable to insomnia. Psychosom. Med. 2010; 72:397-403. [PubMed: 20368477]

First, MB., Gibbon, M., Spitzer, RL., Williams, JBW. Structured Clinical Interview for DSM-IV-TR Axis I Disorders-Non-Patient Edition (SCID-I/NP). Biometrics Research Department, New York State Psychiatric Institute New York; NY: 2007.

Ford DE, Kamerow DB. Epidemiologic study of sleep disturbances and psychiatric disorders. An opportunity for prevention? JAMA. 1989; 262:1479-1484. [PubMed: 2769898]

Fox MD, Raichle ME. Spontaneous fluctuations in brain activity observed with functional magnetic resonance imaging. Nature reviews. 2007; 8:700-711.

Fox MD, Snyder AZ, Vincent JL, Corbetta M, Van Essen DC, Raichle ME. The human brain is intrinsically organized into dynamic, anticorrelated functional networks. Proc. Natl. Acad. Sci. U. S. A. 2005; 102:9673-9678. [PubMed: 15976020]

Fox MD, Zhang D, Snyder AZ, Raichle ME. The global signal and observed anticorrelated resting state brain networks. J. Neurophysiol. 2009; 101:3270-3283. [PubMed: 19339462]

Graham BM, Milad MR. The study of fear extinction: implications for anxiety disorders. Am. J. Psychiatry. 2011; 168:1255-1265. [PubMed: 21865528]

Hardee JE, Thompson JC, Puce A. The left amygdala knows fear: laterality in the amygdala response to fearful eyes. Social cognitive and affective neuroscience. 2008; 3:47-54. [PubMed: 19015094]

Harvey AG. A cognitive model of insomnia. Behav. Res. Ther. 2002; 40:869-893. [PubMed: 12186352] 
Harvey AG. Sleep and circadian functioning: critical mechanisms in the mood disorders? Annual review of clinical psychology. 2011; 7:297-319.

Huang Z, Liang P, Jia X, Zhan S, Li N, Ding Y, Lu J, Wang Y, Li K. Abnormal amygdala connectivity in patients with primary insomnia: evidence from resting state fMRI. Eur. J. Radiol. 2012; 81:1288-1295. [PubMed: 21458943]

Jansson-Frojmark M, Lindblom K. A bidirectional relationship between anxiety and depression, and insomnia? A prospective study in the general population. J. Psychosom. Res. 2008; 64:443-449. [PubMed: 18374745]

Jenkinson M, Beckmann CF, Behrens TE, Woolrich MW, Smith SM. Fsl. Neuroimage. 2012; 62:782790. [PubMed: 21979382]

Johnson EO, Roth T, Breslau N. The association of insomnia with anxiety disorders and depression: exploration of the direction of risk. J. Psychiatr. Res. 2006; 40:700-708. [PubMed: 16978649]

Kales A, Caldwell AB, Soldatos CR, Bixler EO, Kales JD. Biopsychobehavioral correlates of insomnia. II. Pattern specificity and consistency with the Minnesota Multiphasic Personality Inventory. Psychosom. Med. 1983; 45:341-356. [PubMed: 6622623]

Kay DB, Karim HT, Soehner AM, Hasler BP, Wilckens KA, James JA, Aizenstein HJ, Price JC, Rosario BL, Kupfer DJ, Germain A, Hall MH, Franzen PL, Nofzinger EA, Buysse DJ. Sleep-wake differences in relative regional cerebral metabolic rate for glucose among patients with insomnia compared with good sleepers. Sleep. 2016; 39:1779-1794. [PubMed: 27568812]

Keller CJ, Bickel S, Honey CJ, Groppe DM, Entz L, Craddock RC, Lado FA, Kelly C, Milham M, Mehta AD. Neurophysiological investigation of spontaneous correlated and anticorrelated fluctuations of the BOLD signal. J. Neurosci. 2013; 33:6333-6342. [PubMed: 23575832]

Khalsa S, Mayhew SD, Przezdzik I, Wilson R, Hale J, Goldstone A, Bagary M, Bagshaw AP. Variability in cumulative habitual sleep duration predicts waking functional connectivity. Sleep. 2016; 39:87-95. [PubMed: 26414900]

Li C, Ma X, Dong M, Yin Y, Hua K, Li M, Li C, Zhan W, Li C, Jiang G. Abnormal spontaneous regional brain activity in primary insomnia: a resting-state functional magnetic resonance imaging study. Neuropsychiatric disease and treatment. 2016a; 12:1371-1378. [PubMed: 27366068]

Li S, Tian J, Bauer A, Huang R, Wen H, Li M, Wang T, Xia L, Jiang G. Reduced integrity of right lateralized white matter in patients with primary Insomnia: A diffusion-tensor imaging study. Radiology. 2016b; 280:520-528. [PubMed: 27045987]

Li Y, Wang E, Zhang H, Dou S, Liu L, Tong L, Lei Y, Wang M, Xu J, Shi D, Zhang Q. Functional connectivity changes between parietal and prefrontal cortices in primary insomnia patients: evidence from resting-state fMRI. Eur. J. Med. Res. 2014; 19:32. [PubMed: 24915847]

Liu WJ, Yin DZ, Cheng WH, Fan MX, You MN, Men WW, Zang LL, Shi DH, Zhang F. Abnormal functional connectivity of the amygdala-based network in resting-state FMRI in adolescents with generalized anxiety disorder. Medical science monitor : international medical journal of experimental and clinical research. 2015; 21:459-467. [PubMed: 25673008]

Milad MR, Quirk GJ. Fear extinction as a model for translational neuroscience: ten years of progress. Annu. Rev. Psychol. 2012; 63:129-151. [PubMed: 22129456]

Milad MR, Wright CI, Orr SP, Pitman RK, Quirk GJ, Rauch SL. Recall of fear extinction in humans activates the ventromedial prefrontal cortex and hippocampus in concert. Biol. Psychiatry. 2007; 62:446-454. [PubMed: 17217927]

Murphy K, Birn RM, Handwerker DA, Jones TB, Bandettini PA. The impact of global signal regression on resting state correlations: are anti-correlated networks introduced? Neuroimage. 2009; 44:893-905. [PubMed: 18976716]

Neckelmann D, Mykletun A, Dahl AA. Chronic insomnia as a risk factor for developing anxiety and depression. Sleep. 2007; 30:873-880. [PubMed: 17682658]

Nie X, Shao Y, Liu SY, Li HJ, Wan AL, Nie S, Peng DC, Dai XJ. Functional connectivity of paired default mode network subregions in primary insomnia. Neuropsychiatric disease and treatment. 2015; 11:3085-3093. [PubMed: 26719693]

Nofzinger EA, Buysse DJ, Germain A, Price JC, Miewald JM, Kupfer DJ. Functional neuroimaging evidence for hyperarousal in insomnia. Am. J. Psychiatry. 2004; 161:2126-2128. [PubMed: 15514418] 
Oathes DJ, Patenaude B, Schatzberg AF, Etkin A. Neurobiological signatures of anxiety and depression in resting-state functional magnetic resonance imaging. Biol. Psychiatry. 2015; 77:385393. [PubMed: 25444162]

Ohayon MM, Caulet M, Lemoine P. Comorbidity of mental and insomnia disorders in the general population. Compr. Psychiatry. 1998; 39:185-197. [PubMed: 9675502]

Ohayon MM, Roth T. Place of chronic insomnia in the course of depressive and anxiety disorders. J. Psychiatr. Res. 2003; 37:9-15. [PubMed: 12482465]

Pace-Schott EF, Germain A, Milad MR. Effects of sleep on memory for conditioned fear and fear extinction. Psychol. Bull. 2015a; 141:835-857. [PubMed: 25894546]

Pace-Schott EF, Germain A, Milad MR. Sleep and REM sleep disturbance in the pathophysiology of PTSD: the role of extinction memory. Biology of mood \& anxiety disorders. 2015b; 5:3. [PubMed: 26034578]

Pace-Schott EF, Kaji J, Stickgold R, Hobson JA. Nightcap measurement of sleep quality in selfdescribed good and poor sleepers. Sleep. 1994; 17:688-692. [PubMed: 7701179]

Pace-Schott EF, Rubin ZS, Tracy LE, Spencer RM, Orr SP, Verga PW. Emotional trait and memory associates of sleep timing and quality. Psychiatry Res. 2015c; 229:999-1010. [PubMed: 26257092]

Pace-Schott EF, Spencer RM, Vijayakumar S, Ahmed NA, Verga PW, Orr SP, Pitman RK, Milad MR. Extinction of conditioned fear is better learned and recalled in the morning than in the evening. J. Psychiatr. Res. 2013; 47:1776-1784. [PubMed: 23992769]

Pace-Schott EF, Stickgold R, Muzur A, Wigren PE, Ward AS, Hart CL, Clarke D, Morgan A, Hobson JA. Sleep quality deteriorates over a binge--abstinence cycle in chronic smoked cocaine users. Psychopharmacology (Berl). 2005; 179:873-883. [PubMed: 15672273]

Peterson A, Thome J, Frewen P, Lanius RA. Resting-state neuroimaging studies: a new way of identifying differences and similarities among the anxiety disorders? Can. J. Psychiatry. 2014; 59:294-300. [PubMed: 25007403]

Pizzagalli DA. Frontocingulate dysfunction in depression: toward biomarkers of treatment response. Neuropsychopharmacology. 2011; 36:183-206. [PubMed: 20861828]

Power JD, Mitra A, Laumann TO, Snyder AZ, Schlaggar BL, Petersen SE. Methods to detect, characterize, and remove motion artifact in resting state fMRI. Neuroimage. 2014; 84:320-341. [PubMed: 23994314]

Rack-Gomer AL, Liu TT. Caffeine increases the temporal variability of resting-state BOLD connectivity in the motor cortex. Neuroimage. 2012; 59:2994-3002. [PubMed: 22032947]

Raichle ME. The restless brain. Brain connectivity. 2011; 1:3-12. [PubMed: 22432951]

Regen W, Kyle SD, Nissen C, Feige B, Baglioni C, Hennig J, Riemann D, Spiegelhalder K. Objective sleep disturbances are associated with greater waking resting-state connectivity between the retrosplenial cortex/ hippocampus and various nodes of the default mode network. J. Psychiatry Neurosci. 2016; 41:295-303. [PubMed: 26809225]

Riemann D. Insomnia and comorbid psychiatric disorders. Sleep medicine. 2007; (8 Suppl 4):S15-20. [PubMed: 18346672]

Riemann D, Spiegelhalder K, Feige B, Voderholzer U, Berger M, Perlis M, Nissen C. The hyperarousal model of insomnia: a review of the concept and its evidence. Sleep medicine reviews. 2010; 14:19-31. [PubMed: 19481481]

Saad ZS, Gotts SJ, Murphy K, Chen G, Jo HJ, Martin A, Cox RW. Trouble at rest: how correlation patterns and group differences become distorted after global signal regression. Brain connectivity. 2012; 2:25-32. [PubMed: 22432927]

Seeley WW, Menon V, Schatzberg AF, Keller J, Glover GH, Kenna H, Reiss AL, Greicius MD. Dissociable intrinsic connectivity networks for salience processing and executive control. J. Neurosci. 2007; 27:2349-2356. [PubMed: 17329432]

Shin LM, Liberzon I. The neurocircuitry of fear, stress, and anxiety disorders. Neuropsychopharmacology. 2010; 35:169-191. [PubMed: 19625997]

Spielberger, CD., Gorsuch, RL., Lushene, RE. Manual for the State-Trait Anxiety Inventory (SelfEvaluation Questionnaire). Consulting Psychologists Press; Palo Alto: 1990. 
Stepanski EJ, Rybarczyk B. Emerging research on the treatment and etiology of secondary or comorbid insomnia. Sleep medicine reviews. 2006; 10:7-18. [PubMed: 16376125]

Tagliazucchi E, Laufs H. Decoding wakefulness levels from typical fMRI resting-state data reveals reliable drifts between wakefulness and sleep. Neuron. 2014; 82:695-708. [PubMed: 24811386]

Tromp DP, Grupe DW, Oathes DJ, McFarlin DR, Hernandez PJ, Kral TR, Lee JE, Adams M, Alexander AL, Nitschke JB. Reduced structural connectivity of a major frontolimbic pathway in generalized anxiety disorder. Arch. Gen. Psychiatry. 2012; 69:925-934. [PubMed: 22945621]

van de Laar M, Verbeek I, Pevernagie D, Aldenkamp A, Overeem S. The role of personality traits in insomnia. Sleep medicine reviews. 2010; 14:61-68. [PubMed: 19897388]

Van Dijk KR, Hedden T, Venkataraman A, Evans KC, Lazar SW, Buckner RL. Intrinsic functional connectivity as a tool for human connectomics: theory, properties, and optimization. J. Neurophysiol. 2010; 103:297-321. [PubMed: 19889849]

Vincent JL, Snyder AZ, Fox MD, Shannon BJ, Andrews JR, Raichle ME, Buckner RL. Coherent spontaneous activity identifies a hippocampal-parietal memory network. J. Neurophysiol. 2006; 96:3517-3531. [PubMed: 16899645]

Wang T, Yan J, Li S, Zhan W, Ma X, Xia L, Li M, Lin C, Tian J, Li C, Jiang G. Increased insular connectivity with emotional regions in primary insomnia patients: a resting-state fMRI study. Eur. Radiol. 2017 Jan.31

Winkelman JW, Plante DT, Schoerning L, Benson K, Buxton OM, O'Connor SP, Jensen JE, Renshaw $\mathrm{PF}$, Gonenc A. Increased rostral anterior cingulate cortex volume in chronic primary insomnia. Sleep. 2013; 36:991-998. [PubMed: 23814335]

Yarkoni T, Poldrack RA, Nichols TE, Van Essen DC, Wager TD. Large-scale automated synthesis of human functional neuroimaging data. Nat Methods. 2011; 8:665-670. [PubMed: 21706013]

Yeo BT, Krienen FM, Sepulcre J, Sabuncu MR, Lashkari D, Hollinshead M, Roffman JL, Smoller JW, Zollei L, Polimeni JR, Fischl B, Liu H, Buckner RL. The organization of the human cerebral cortex estimated by intrinsic functional connectivity. J. Neurophysiol. 2011; 106:1125-1165. [PubMed: 21653723]

Zhou F, Huang S, Gao L, Zhuang Y, Ding S, Gong H. Temporal regularity of intrinsic cerebral activity in patients with chronic primary insomnia: a brain entropy study using resting-state fMRI. Brain and behavior. 2016; 6:e00529. [PubMed: 27781143]

Psychiatry Res. Author manuscript; available in PMC 2018 July 30. 


\section{Highlights}

- $\quad$ Resting-state fMRI compared controls, insomniacs and Generalized Anxiety groups

- Whole-brain connectivity of 6 fear-related seed regions compared between groups

- $\quad$ Using ANOVA \& cluster-size thresholds, only L amygdala-rostral ACC differentiated

- Amygdala-rACC connectivity significantly greater in controls vs. insomniacs and GAD

- Connectivity in insomniacs intermediate between controls and GAD 


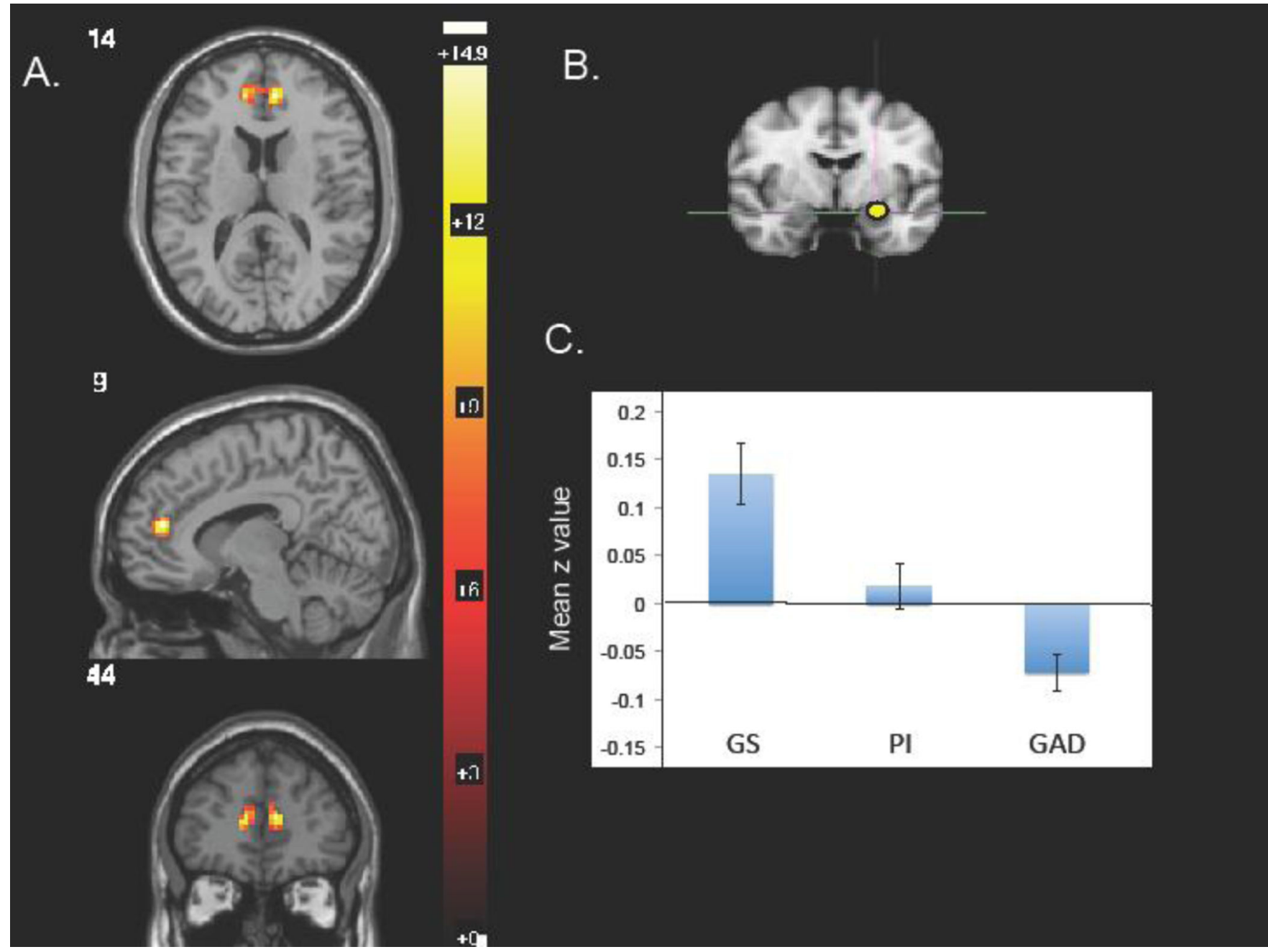

Fig 1.

Using 1-way, 3-level ANOVA, a 76-voxel region in the rostral ACC (rACC) showed significant differences among the 3 groups for whole-brain connectivity with the left amygdala seed. A. rACC region of ANOVA main effect with peak voxel at 9, 44,14 and a CDT of $p=0.005$; B. L amygdala seed; C. extracted mean $z$ values for the rACC cluster connectivity with the $\mathrm{L}$ amygdala seed. 


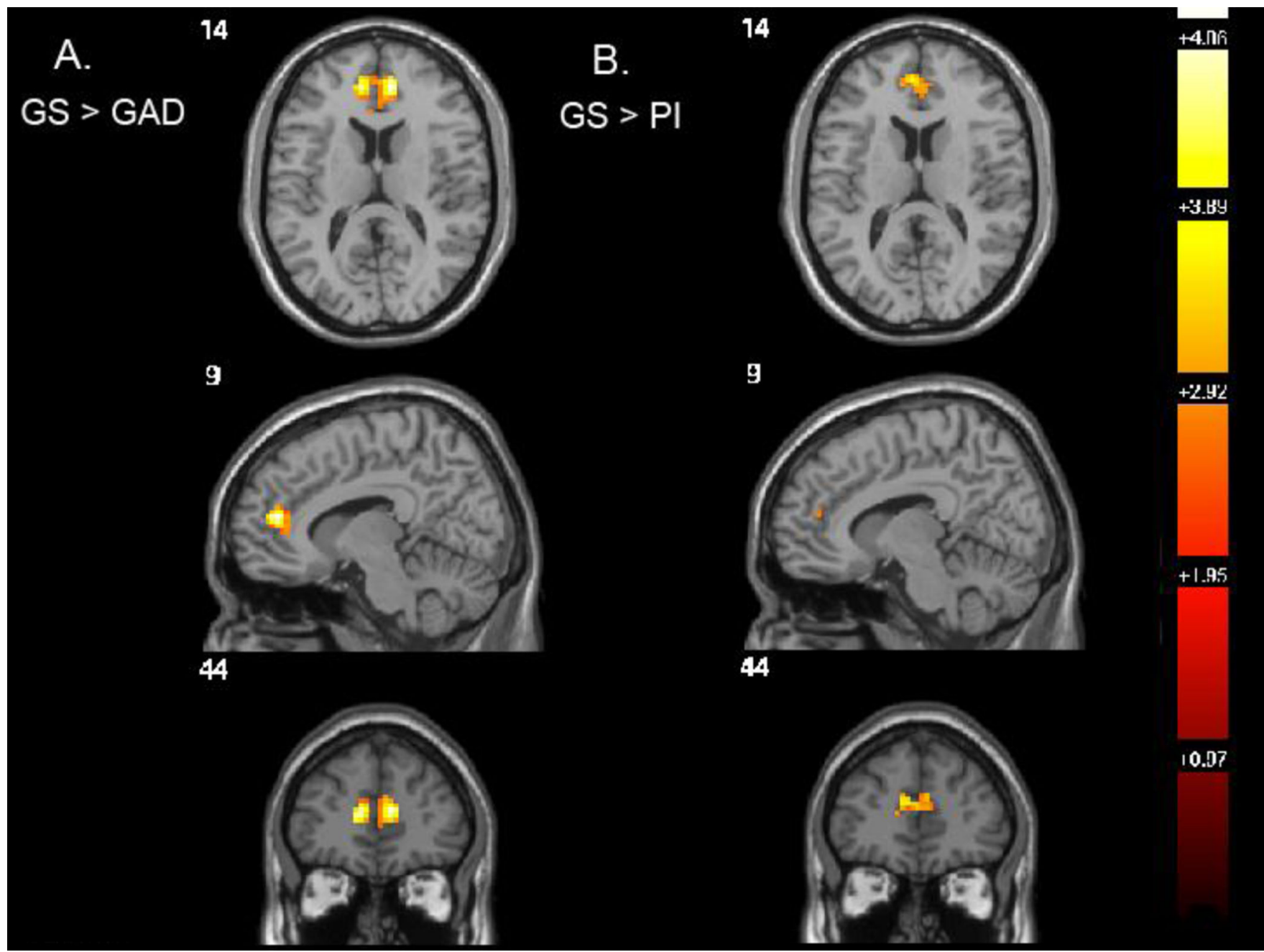

Fig 2.

Pair-wise, post-hoc group comparisons using t-tests computed by SPM8 within the ANOVA comparing all three groups and displayed at the level of the peak voxel in the ANOVA main effect $(9,44,14)$. A. GS > GAD, CDT $p=0.005$, cluster size 143 , peak voxel $-9,44,14$; B. GS > PI, CDT $p=0.007$, cluster size 74, peak voxel $-6,47,17$. 

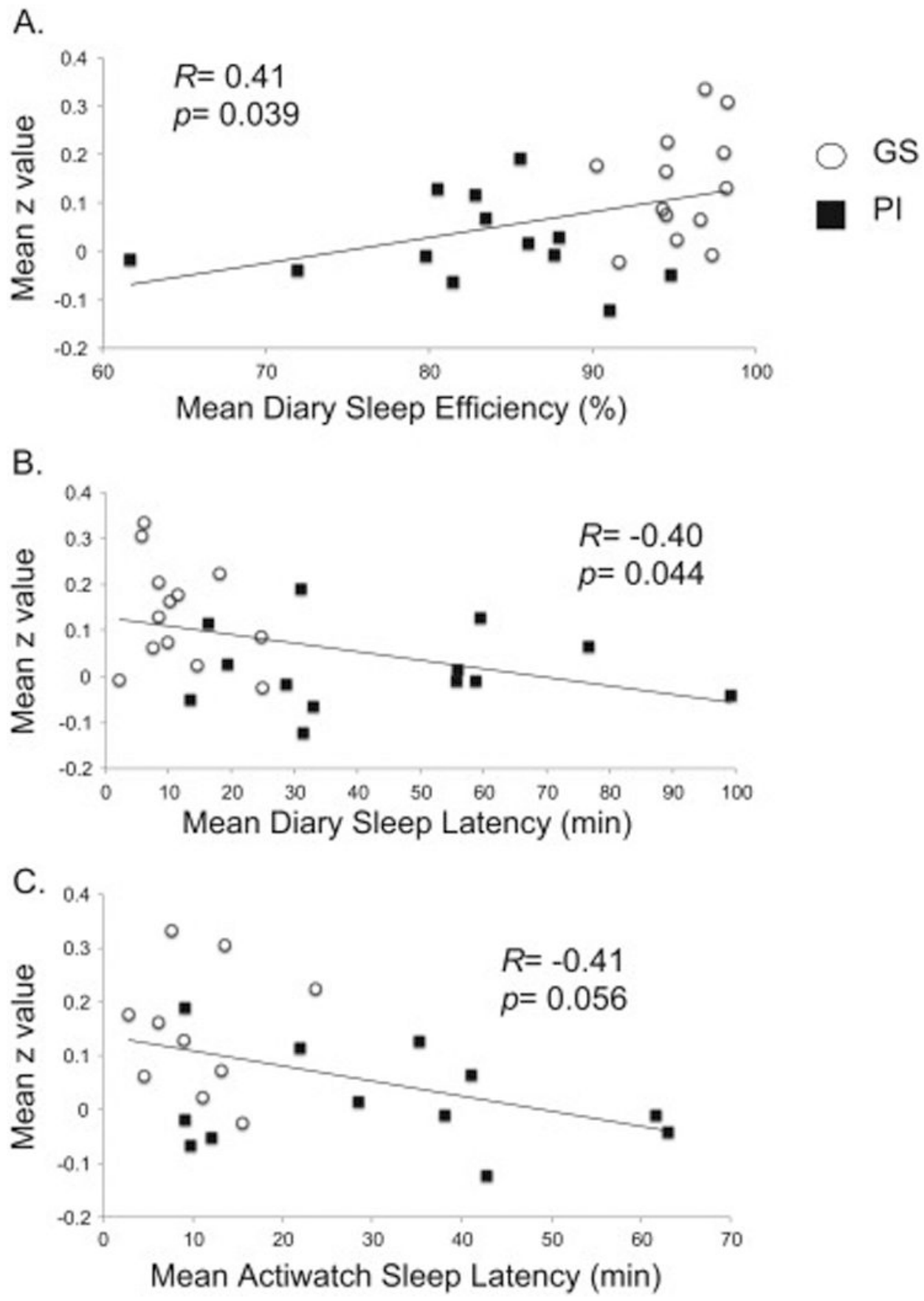

Fig 3.

Simple regression, across GS and PI subjects, of sleep parameters against the extracted mean $Z$-value of the ANOVA main effect. A. Diary-based sleep efficiency, B. Diary-based sleep latency, C. Actigraphy-based sleep latency.

Psychiatry Res. Author manuscript; available in PMC 2018 July 30. 
A.

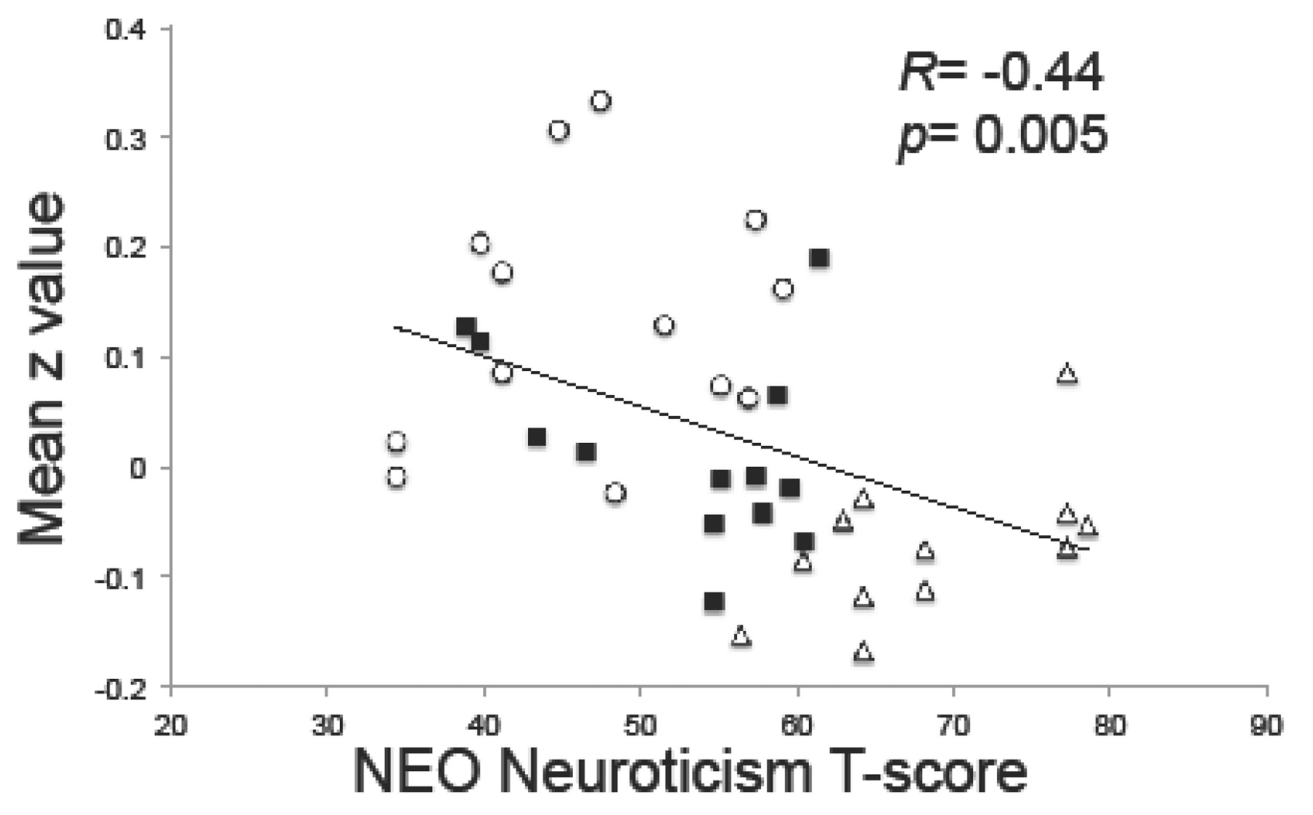

6 GS
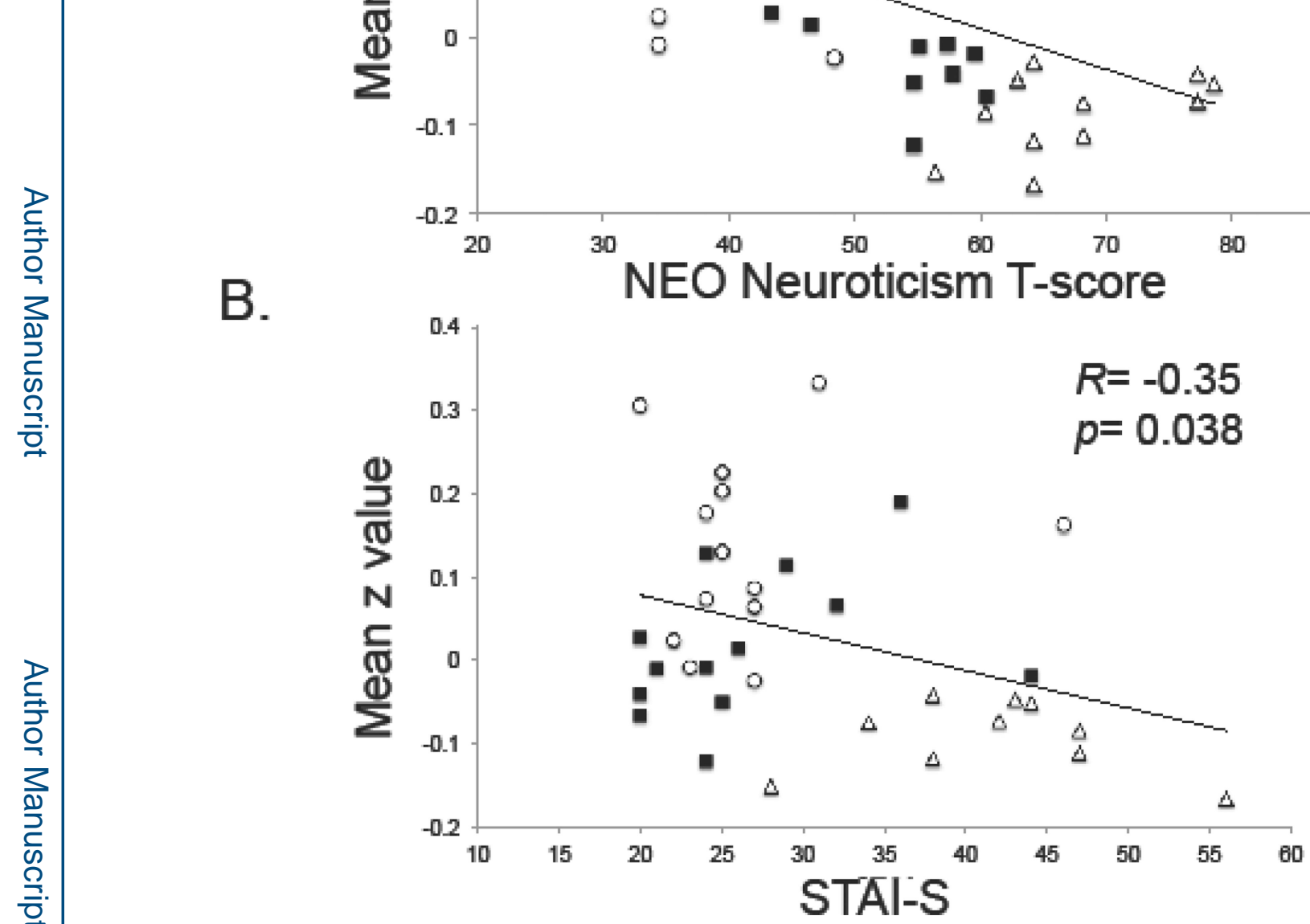

Fig 4.

Simple regression, across all subjects, of trait and state measures of anxiety against the extracted mean z-value from the ANOVA main effect. A. T-scores for Neuroticism measured using the NEO-PI-R or the NEO-FFI. B. Spielberger State-Trait Inventory-State-portion score reported 30-60 min before beginning resting-state scan. 


\section{Table 1}

Means and standard deviations of demographic, sleep measurements (GS and PI only), indices of trait (NEO neuroticism) and pre-scan state (STAI-S) anxiety, as well as quality control measures for resting state scans.

\begin{tabular}{|c|c|c|c|c|}
\hline & GS & PI & GAD & ANOVA, $t$ test \\
\hline Total & 13 & 13 & 12 & \\
\hline Number males & 2 & 2 & 2 & \\
\hline Mean age (yr) & $35(15.0)$ & $35.2(15.7)$ & $30.2(10.3)$ & n.s., $p=0.60$ \\
\hline Median age (yr) & 29 & 27 & 26 & \\
\hline Age range (yr) & $21-60$ & $20-63$ & $20-51$ & \\
\hline ISI & $0.77(1.67)$ & $18.83(3.79)^{a}$ & & $p \leq 0.0001$ \\
\hline PSQI & $1.69(0.95)$ & $10.68(3.09)^{a}$ & & $p \leq 0.0001$ \\
\hline ESS & $3.54(2.57)$ & $8.69(6.18)$ & & $p=0.01$ \\
\hline MEQ & $52.77(8.67)$ & $48.08(9.58)$ & & n.s., $p=0.20$ \\
\hline Diary TST (min) & $454.12(46.26)$ & $399.46(80.83)$ & & $p \leq 0.0001$ \\
\hline Diary SE (\%) & $95.36(2.48)$ & $82.66(8.45)$ & & $p=0.045$ \\
\hline Diary SOL (min) & $11.78(7.03)$ & $44.51(25.53)$ & & $p=0.0002$ \\
\hline midpoint (min) & 209.84 (61.93) & $239.08(55.73)$ & & n.s. $p=0.22$ \\
\hline Actiwatch TST & $391.12(60.77)^{b}$ & $408.64(42.00)^{a}$ & & n.s. $p=0.45$ \\
\hline Actiwatch SE & $87.55(5.50)^{b}$ & $81.48(4.44)^{a}$ & & $p=0.005$ \\
\hline Actiwatch SOL & $10.78(6.12)^{b}$ & $31.04(19.33)^{a}$ & & $p=0.01$ \\
\hline midpoint & $185.14(47.98)^{b}$ & $238.69(58.73)^{b}$ & & $p=0.03$ \\
\hline PSG TST & 389.25 (69.44) & $326.18(147.89)$ & & n.s., $p=0.64$ \\
\hline PSG WASO & $42.31(30.92)$ & $34.75(43.90)$ & & n.s. $p=0.86$ \\
\hline PSG \% N1 & $9.09(4.48)$ & $7.96(3.94)$ & & n.s., $p=0.89$ \\
\hline PSG \% N2 & $57.28(8.15)$ & $46.81(19.20)$ & & n.s., $p=0.23$ \\
\hline PSG \% N3 & $15.93(9.28)$ & $17.58(10.98)$ & & n.s., $p=0.29$ \\
\hline PSG \%REM & $17.68(8.33)$ & $15.36(8.14)$ & & n.s., $p=0.93$ \\
\hline STAI-S & $26.62(6.43)$ & $26.54(7.14)$ & $41.70 * b$ & $p \leq 0.0001$ \\
\hline NEO-N, $T$ score & $47.01(8.59)$ & $52.92(7.97)^{\dagger}$ & $68.25(7.56)^{*}$ & $p \leq 0.0001$ \\
\hline Mn. movement & $0.08(0.05)$ & $0.08(0.04)$ & $0.08(0.04)$ & n.s., $p=0.94$ \\
\hline Tot. movement & $0.92(0.42)$ & $1.19(0.60)$ & $1.31(1.09)$ & n.s., $p=0.43$ \\
\hline Tot. rotation & $0.16(0.01)$ & $0.02(0.01)$ & $0.02(0.02)$ & n.s., $p=0.46$ \\
\hline
\end{tabular}

ISI - Insomnia Severity Index; PSQI - Pittsburgh Sleep Quality Index; ESS - Epworth Sleepiness Scale; MEQ - Morningness-Eveningness Questionnaire; TST - mean total sleep time; SE - mean sleep efficiency; SOL - mean sleep onset latency; midpoint - mean minutes past midnight; PSG - polysomnography, average of two nights; WASO - mean wake time after sleep onset; N1-N3 - non-rapid eye movement sleep stages 1-3; REM - raid eye movement sleep; STAI-S - Spielberger State-Trait Anxiety Inventory, Connectivity in Insomnia and Generalized Anxiety State Version; NEO-N - $T$ score based on population means for NEO Personality Inventory, Revised (GS and PI) or NEO Five-Factor Inventory (GAD); Mn. - mean; Tot. - Total;

${ }^{\dagger}$ PI differs from GS, $\mathrm{p}<0.10$

*GAD significantly greater than GS and PI, $p=0.0001$;

${ }^{a}=12$,

Psychiatry Res. Author manuscript; available in PMC 2018 July 30. 
${ }^{b}{ }_{N=10}$

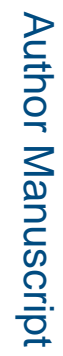

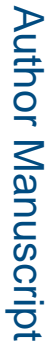

를

로을

Psychiatry Res. Author manuscript; available in PMC 2018 July 30. 